\title{
Acondicionamiento de becerros previo a la recría bajo pastoreo en trópico seco: efectos sobre el peso corporal y la condición sanitaria
}

\section{Conditioning around weaning of calves grazing in the dry tropic: effects upon body weight and health condition}

\author{
Rafael Guarneros Altamirano ${ }^{a}$ Erasmo Gutiérrez Ornelas ${ }^{b}$, Hugo Bernal Barragán ${ }^{b *}$, Ramiro Avalos Ramírez ${ }^{\mathrm{b}}$, \\ Epigmenio Castillo Gallegos ${ }^{c}$, Emilio Olivares Sáenz ${ }^{b}$
}

\begin{abstract}
RESUMEN
Se realizaron tres experimentos ( 2 en época seca y 1 en época de lluvias) utilizando 96 becerros (Simmental $X$ Cebú) para evaluar el efecto del acondicionamiento realizado durante 112 días (del día 28 predestete al día 84 posdestete). En cuatro períodos de 28 días cada uno, se evaluó peso y condición corporal de los animales, nitrógeno ureico (NU) y glucosa (GS) en suero sanguíneo, así como la incidencia de enfermedades (IE) de becerros en pastoreo. Resultados de peso corporal, ganancia de peso (GDP) acumulativa, NU y GS se evaluaron con ANOVA en un diseño factorial de 2 tratamientos x 2 sexos; IE se analizó con Ji-cuadrada. No hubo diferencia de peso $(P=0.552)$ ni de CC $(P=0.891)$ de las vacas debido a tratamientos. No hubo interacción acondicionamiento $x$ sexo $(P=0.853)$ ni efecto de sexo $(P=0.586)$ sobre el crecimiento de becerros (media $=357 \mathrm{~g} /$ día $)$. El acondicionamiento originó mejor GDP (507 vs $281 \mathrm{~g} /$ día; $P=0.001)$ en la época seca y menor IE $(P=0.001)$ que el tratamiento testigo. En época de lluvias el acondicionamiento incrementó $31 \%$ el crecimiento en 112 días respecto al testigo (370 vs $281 \mathrm{~g} /$ día; $P=0.026$ ). Las concentraciones de NU $(P=0.425)$ y GS $(P=0.270)$ fueron similares entre tratamientos. En conclusión, el acondicionamiento de becerros mejoró la GDP posdestete, redujo la incidencia de enfermedades en becerros, y la disminución de peso y condición corporal en sus madres, durante la época seca.
\end{abstract}

PALABRAS CLAVE: Acondicionamiento de becerros, Ganancia de peso, Trópico seco, Pastoreo.

\begin{abstract}
Three experiments (two in the dry season and one in the rainy season) were conducted utilizing 96 Simmental $x$ Zebu calves, with the aim to evaluate the effect of preconditioning during $112 \mathrm{~d}$ starting at d 28 preweaning. In four periods of $28 \mathrm{~d}$ each, body weight and body condition score of the animals, blood urea nitrogen (BUN) and glucose (SG) in serum, as well as disease frequency in grazing calves were evaluated. Data of BW, cumulative body weight gain (BWG) BUN, and SG were analyzed with ANOVA in a 2 treatments $\times 2$ sex factorial arrangement; morbility was analyzed by Ji square. $B W(P=0.552)$ and $B C S(P=0.891)$ of nursing cows did not vary due to treatments. Interaction conditioning $x$ sex was not significant $(P=0.853)$, and sex did not influenced growth of calves (mean=357 g/d). Conditioning led to better BWG (507 vs $281 \mathrm{~g} / \mathrm{d} ; P=\mathbf{0 . 0 0 1})$ in the dry season and less morbility $(P=0.001)$ than the control group. During the rainy season preconditioning increased $31 \%$ the cumulative BWG in $112 \mathrm{~d}$ compared to control (370 vs $281 \mathrm{~g} / \mathrm{d} ; P=0.026)$. Concentrations of BUN $(P=0.425)$ and SG $(P=0.270)$ were similar between treatments. In conclusion, preconditioning of calves improved BWG postweaning, reduced morbility and loss of weight and BCS of lactating cows during the dry season.
\end{abstract}

KEY WORDS: Pre-weaning, Conditioning of calves, Body weight gain, Dry tropics.

Recibido el 4 de enero de 2016. Aceptado el 19 de abril de 2016.

${ }^{a}$ Instituto Nacional de Investigaciones Forestales, Agrícolas y Pecuarias (INIFAP), Campo Experimental Las Huastecas, Altamira, Tamaulipas, México.

bUniversidad Autónoma de Nuevo León, Facultad de Agronomía y Facultad de Medicina Veterinaria y Zootecnia. México. Nuevo León, México.

'Universidad Nacional Autónoma de México, Facultad de Medicina Veterinaria y Zootecnia, Martínez de la Torre, Veracruz, México.

*Autor para correspondencia: hubernal05@gmail.com 


\section{INTRODUCCIÓN}

En México, la ganadería bovina productora de carne se conforma, principalmente, de tres segmentos: sistema vaca-becerro ${ }^{(1)}$, el repasto de los becerros después del destete y la finalización del ganado en corral. Generalmente, en el trópico ocurre el destete a los siete meses de edad, cuando los becerros pesan entre 140 y $160 \mathrm{~kg}^{(2,3)}$. Durante el paso del destete al repasto, los becerros sufren cambios en el régimen de alimentación, en su manejo y ambiente, que les provocan estrés ${ }^{(4)}$, dando esto como resultado bajos aumentos de peso y presencia de enfermedades ${ }^{(5)}$.

El acondicionamiento de los becerros previo al destete $^{(6)}$ consiste en la aplicación de vitaminas liposolubles, suplementación alimenticia, la realización de diferentes prácticas de manejo que ayudan al control de parásitos internos y externos, así como la inmunización contra diferentes enfermedades ${ }^{(7,8)}$, que ayudan a disminuir el estrés, reducen la incidencia de enfermedades y mejoran el comportamiento de los animales en su desarrollo ${ }^{(9,10)}$. La información generada en México sobre el acondicionamiento predestete de becerros resalta la inmunización e identificación en el becerro $^{(11)}$ y la suplementación predestete ${ }^{(12,13)}$, aunque falta información sobre su efecto en la fase posdestete.

El contenido de nitrógeno ureico en la sangre puede ser utilizado como indicador de la eficiencia de utilización del nitrógeno ingerido por los animales $^{(14)}$. El nivel y tipo de suministro energético pueden influir sobre el contenido de glucosa sanguínea y en los datos productivos de animales rumiantes $^{(15)}$.

Considerando que en México no se cuenta con protocolos para promover un mejor comportamiento del becerro, previo a su entrada al repasto ${ }^{(12,16)}$ y con ello aprovechar el potencial existente en las regiones tropicales del país, el objetivo del presente estudio fue evaluar el efecto del acondicionamiento en becerros Simmental x Cebú antes del destete, y la suplementación posdestete, sobre la ganancia diaria de peso en el período de recría y sobre las concentraciones séricas de glucosa y nitrógeno ureico, así como la incidencia de enfermedades en becerros mantenidos en el trópico seco durante las épocas seca y de lluvias. Además, evaluar los cambios de peso y la condición corporal de las madres de estos becerros.

\section{MATERIAL Y MÉTODOS}

\section{Descripción del área de estudio}

Se trabajó en dos ranchos comerciales ubicados en Aldama, Tamaulipas, con clima semicálido subhúmedo, $A(C) w_{1}{ }^{(17)}$, con una temperatura promedio de $28^{\circ} \mathrm{C}$ y una precipitación pluvial de 800 $\mathrm{mm} /$ año. Dos experimentos (Exp 1 y 3 ) se realizaron durante dos períodos de sequía (enero a mayo 2012 y 2013) en el rancho "Don Enrique", ubicado en el km 37 de la carretera Aldama-Barra del Tordo interior 7, a $23^{\circ} 03^{\prime} 23.64^{\prime \prime} \mathrm{N}$ y $97^{\circ} 49^{\prime} 11.00^{\prime \prime} \mathrm{O}$ y a una altitud de $15 \mathrm{msnm}$. En el rancho "Laguna Colorada", ubicado en el km 23 de la carretera

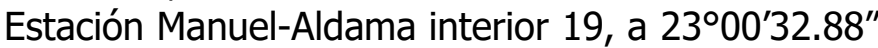
$\mathrm{N}$ y $98^{\circ} 10^{\prime} 07.60^{\prime \prime} \mathrm{O}$ y a $232 \mathrm{msnm}$, se evaluó el efecto del acondicionamiento durante el período de lluvias del 2012 (Exp 2).

Las temperaturas mínima, máxima y promedio fueron $14.2,31.4$, y $25.9^{\circ} \mathrm{C}(\operatorname{Exp} 1), 14.2,33.0$ y $27.7^{\circ} \mathrm{C}(\operatorname{Exp} 2)$, y $9.4,35.0$, y $30.5^{\circ} \mathrm{C}(\operatorname{Exp} 3)$. La precipitación registrada fue de $212.7,436$, y 102.5 $\mathrm{mm}$ (Exp 1, 2 y 3, respectivamente).

\section{Manejo animal}

Se utilizaron 96 becerros lactantes de aproximadamente seis meses de edad, de la cruza Simmental x Cebú, nacidos en invierno de 2012 y 2013 (época seca) y verano de 2012 (época de lluvias). En cada experimento los becerros se identificaron en forma individual, asignándose aleatoriamente 16 animales ( 7 machos y 9 hembras) a cada uno de los dos tratamientos: $\mathrm{T} 1=$ testigo $\mathrm{sin}$ acondicionamiento; $\mathrm{T} 2=$ becerros acondicionados durante un período de 112 días ( 28 días antes del destete a 84 días después del destete).

El acondicionamiento consistió en la aplicación de las siguientes prácticas: desparasitación vía subcutánea (s.c.) con ivermectina (Dectiver Premium, Lapisa) a razón de $1 \mathrm{ml} / 50 \mathrm{~kg}$ de peso corporal; $2 \mathrm{ml}$ de vitaminas $\mathrm{A}_{1} \mathrm{D}_{3}$, y $\mathrm{E}$ por vía 
intramuscular (i.m.); aplicación de $5 \mathrm{ml} /$ animal vía s.c. de la bacterina Ultrabac 7/Sumobac (Pfizer Animal Health) para prevenir enfermedades del complejo clostridial (Clostridium chavoei, C. septicum, C. novyi, C. sordellii, C. perfingens Tipos C\&D, así como Haemophilus somnus), y aplicación s.c. de $5 \mathrm{ml} /$ animal de vacuna contra rinotraqueitis viral bovina, diarrea viral bovina, pneumonías (PI3) y virus respiratorio sincicial bovino. Los animales se bañaron por inmersión en Flumetrina (Bayticol) a una dosis de $1 \mathrm{~L} / 1000 \mathrm{~L}$ de agua, para el control de garrapata. Al grupo acondicionado también se le suplementó con un concentrado de $35 \%$ de PC y $2.85 \mathrm{Mcal} \mathrm{EM} / \mathrm{kg} \mathrm{MS}$, elaborado a base de $75 \%$ de pasta de soya, $17 \%$ de sorgo molido, $5 \%$ de melaza y $3 \%$ de sal mineralizada, ofrecido a razón de 20 $\mathrm{g} / \mathrm{kg} \mathrm{PV}$ P.75/día, desde el día 28 antes del destete hasta el día 84 posdestete ${ }^{(18)}$. El mismo concentrado se utilizó para las épocas de lluvia y de sequía.

En la fase predestete el suplemento se ofreció diariamente al lote de animales del T2 en comederos móviles tipo "creep feeding"(19), y después del destete, se ofreció en comederos abiertos con, al menos, $1 \mathrm{~m}$ de espacio de comedero por animal, ajustando cada 14 días la cantidad de suplemento ofrecido por animal/día, de acuerdo al peso vivo estimado con base en el registro anterior de peso y la ganancia diaria proyectada para el periodo en cuestión.

Los registros de peso de los animales (becerros y vacas), así como la toma de muestras sanguíneas se realizaron a las $0700 \mathrm{~h}$, previo ayuno de 14 a 16 $\mathrm{h}$, al iniciar los experimentos (a los 28 días antes del destete), así como el día de destete (día 0) y a los días 28, 56, 84 y 112 posdestete. Se evaluó la condición corporal (CC) a las vacas al inicio y a los 28 días de acuerdo con la metodología descrita

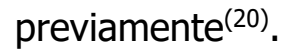

Los dos grupos de animales (no acondicionados y acondicionados) se colocaron con sus madres en diferentes praderas hasta ser destetados, a los siete meses de edad aproximadamente. Después del destete, los grupos de estudio continuaron separados en potreros con buena disponibilidad de pastos Guinea (Panicum maximum) y Estrella Africana (Cynodon plecstostachyus). En las fechas antes señaladas se colectaron cinco muestras de pastos al azar de acuerdo con la metodología descrita por Bobadilla et $a^{(21)}$, utilizando un cuadrante de $0.5 \mathrm{~m}^{2}$ y cortando el forraje disponible hasta una altura de $5 \mathrm{~cm}$, en las praderas correspondientes a cada tratamiento, para analizar en laboratorio el valor nutricional de los pastos ahí presentes $^{(22,23) \text {. }}$

A cada animal se le extrajeron dos muestras de sangre, mediante punción de la vena coccígea. Para la determinación de glucosa (GS), la sangre se obtuvo utilizando un tubo Vacutainer monojection de $10 \mathrm{ml}$, con $15 \%$ de EDTA $\left(\mathrm{K}_{3}\right)$. El plasma sanguíneo se analizó inmediatamente después de haber obtenido la muestra, para determinar glucosa, usando un equipo marca Accu-Chek performa (Roche, México), con tiras reactivas y chip de codificación.

La muestra para analizar nitrógeno ureico (UN) en sangre, se obtuvo en tubos BD Vacutainer ${ }^{\circledR}$ serum (STERILE Interior). El suero se separó de la muestra coagulada por centrifugación a 2,000 rpm, y se congeló a $-20{ }^{\circ} \mathrm{C}$ hasta su análisis. La determinación del UN fue llevada a cabo por el método de valoración colorimétrica de Berthelot modificado (fenol-hipoclorito) (Randox, México). La absorbancia a $600 \mathrm{~nm}$ de longitud de onda se determinó en un espectrofotómetro SP-830 plus Modelo SM110215 (Barnstead, Iowa, USA).

La incidencia de enfermedades se determinó diariamente en cada grupo e individualmente en las fechas de pesaje, mediante la inspección y evaluación clínica o identificación de animales enfermos, que fueran diagnosticados con flujo nasal y fiebre (temperatura mayor de $37.5^{\circ} \mathrm{C}$ ), apatía, cojera o tristeza(24), procediendo a tratarlos con antibiótico (Fluvicina, 2 Millones UI/animal/24 h) y antipirético (Dipirona, $5 \mathrm{ml} /$ animal/24 h) durante 2 o 3 días.

\section{Análisis económico}

La información económica recabada para los animales acondicionados fue de tres rubros de gastos: control o manejo sanitario, suplemento alimenticio y mano de obra. Se consideraron los costos del desparasitante, vacunas, vitaminas y material utilizado, que dio un total de \$23.09 MN/animal. El suplemento se consumió en su 
totalidad (no hubo rechazo) y se registró un consumo promedio de $106.27 \mathrm{~kg}$. El suplemento tuvo un costo de $\$ 7.17 / \mathrm{kg}$, que multiplicado por el consumo, dio un costo de $\$ 761.95 /$ animal. El costo de mano de obra ( $\$ 130.18 /$ animal) se calculó considerando el pago mensual del personal en cada unidad de producción (vaqueros y caporales) para el número de animales que manejaron durante los cinco meses que duró el estudio. Para los animales no acondicionados solo se consideró el gasto de mano de obra ( $\$ 130.18 /$ animal), pues no se tuvieron gastos de manejo sanitario ni suplementación. Para los cálculos económicos se consideró el precio ponderado a nivel nacional al mes de mayo de 2015, de $\$ 40.26 / \mathrm{kg}$, publicado por la Secretaría de Economía(25).

\section{Análisis estadístico}

El análisis estadístico de los datos experimentales para cada período se realizó mediante un arreglo factorial $2 \times 2$ (dos niveles de acondicionamiento y dos sexos), teniendo un total de 16 unidades experimentales (animales) para cada tratamiento.

Se evaluaron las variables: ganancia total de peso, ganancia diaria de peso (GDP) acumulada en cuatro períodos: 1 (desde 28 días antes del destete hasta el destete), 2 (desde 28 días antes del destete hasta 28 días posdestete), 3 (desde 28 días antes del destete hasta 56 días posdestete) y 4 (desde 28 días antes del destete hasta 84 días posdestete, es decir durante los 112 días del experimento). La concentración de glucosa (GS) y de nitrógeno ureico (NU) en sangre, se evaluaron para cada muestreo por separado (al inicio, al destete, a los 28,56 y 84 días posdestete). Por este motivo no se incluyó el factor período en el modelo utilizado:

$$
\mathrm{Y}_{\mathrm{ij}}=\mu+\mathrm{T}+\mathrm{S}+\mathrm{T} \times \mathrm{S}+\varepsilon(\mathrm{a})
$$

Donde $Y_{i j k}=$ variable dependiente; $\mu=$ media general; $\mathrm{T}=$ efecto del i-ésimo tratamiento; $\mathrm{S}=$ efecto del j-ésimo sexo; $\mathrm{T} \times \mathrm{S}=$ efecto de la interacción del i-ésimo tratamiento y el j-ésimo sexo; $\varepsilon(\mathrm{a})=$ error .

Se utilizó el software SPSS para Windows versión $17^{(26)}$. Cuando existió efecto significativo $(P<0.05)$ para alguna de las variables, se realizó la comparación de medias mediante la prueba de t de Student ${ }^{(27)}$. La frecuencia de animales enfermos de las vías respiratorias en el hato experimental en las diferentes épocas y tratamientos se analizó mediante la prueba de Ji-cuadrada.

\section{RESULTADOS}

\section{Peso y condición corporal de las vacas}

El peso de las vacas al inicio y al destete fue similar entre tratamientos (Cuadro 1). En los experimentos 1 y 3, durante los 28 días previos al destete, las pérdidas de peso de las vacas madres de becerros sin acondicionamiento fueron entre 15 y $17 \mathrm{~kg}$ de peso, mientras que las madres de los becerros acondicionados y suplementados solo perdieron entre 5 y $7 \mathrm{~kg},(P>0.05)$. En el Exp 2 (época de lluvias), durante los 28 días previos al destete, las madres de becerros incrementaron su peso en $20.6 \mathrm{~kg}$ (testigo) o $28.3 \mathrm{~kg}$ (acondicionados)

Cuadro 1. Peso $(\mathrm{kg})$ y condición corporal (CC) de las madres de becerros con y sin acondicionamiento durante 28 días previos al destete

\begin{tabular}{lrrrr}
\hline Variables & \multicolumn{5}{c}{ Acondicionamiento } \\
\multicolumn{7}{c}{ Sin } & Con & EEM & $P$ \\
\hline Exp 1, época seca 2012 & & & \\
Peso inicial & 456.10 & 441.60 & 16.90 & 0.543 \\
CC inicial & 4.00 & 4.01 & 0.17 & 0.987 \\
Peso al destete & 440.30 & 434.30 & 16.60 & 0.797 \\
CC al destete & 3.60 & 3.75 & 0.12 & 0.389 \\
Cambio de peso & -15.80 & -7.30 & 6.29 & 0.342 \\
Cambio de CC & -0.40 & -0.25 & 0.16 & 0.495 \\
& & & & \\
Exp 2, época de lluvias 2012 & & & \\
Peso inicial & 460.90 & 422.00 & 16.47 & 0.104 \\
CC inicial & 4.34 & 3.93 & 0.16 & 0.088 \\
Peso al destete & 481.50 & 450.30 & 21.21 & 0.302 \\
CC al destete & 3.97 & 3.73 & 0.16 & 0.298 \\
Cambio de peso & +20.60 & +28.30 & 19.72 & 0.784 \\
Cambio de CC & -0.37 & -0.25 & 0.24 & 0.623 \\
\multicolumn{7}{l}{ Exp 3, época seca 2013} & & & \\
Peso inicial & 512.70 & 498.10 & 48.97 & 0.584 \\
CC inicial & 3.68 & 3.62 & 0.13 & 0.745 \\
Peso al destete & 484.60 & 493.20 & 18.34 & 0.738 \\
CC al destete & 3.47 & 3.59 & 0.12 & 0.507 \\
Cambio de peso & -16.60 & -4.90 & 5.37 & 0.122 \\
Cambio de CC & -0.21 & -0.03 & 0.13 & 0.346 \\
\hline
\end{tabular}


$($ EEM $\pm 19.72 \mathrm{~kg} ; P=0.784)$. Considerando los tres experimentos, la CC de las vacas no disminuyó entre el inicio de la prueba y el destete debido a los tratamientos evaluados.

\section{Peso de los becerros}

No hubo interacción de sexo x tratamiento, $\mathrm{ni}$ efecto de sexo sobre el peso de los becerros a los 84 días posdestete, por lo que se presentan únicamente los resultados del efecto del acondicionamiento sobre las variables evaluadas. En los Exp 1 y 3, realizados en las épocas secas, se registraron pesos similares entre tratamientos al destete y a los 28 días posdestete (Figura 1). A los 56 y 84 días posdestete,

Figura 1. Peso corporal $(\mathrm{kg})$ de becerros con acondicionamiento (líneas azules) y sin acondicionamiento (líneas rojas) en tres experimentos

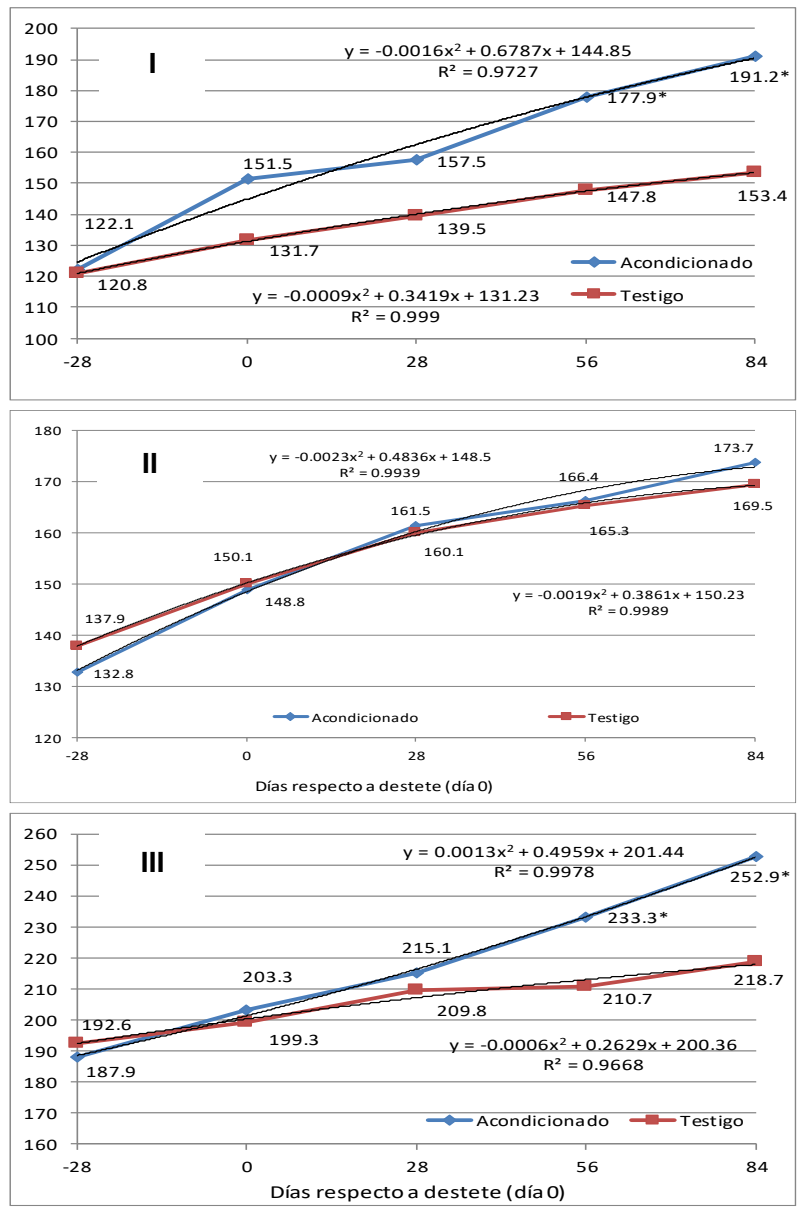

I= época seca 2012, pesos periodo $3(P=0.019)$, pesos periodo $4(P=0.0004)$. $\|=$ época de lluvias $2102(P>0.05)$. III= época seca 2013, pesos periodo $3(P=0.048)$, pesos periodo $4(P=0.006)$. los becerros acondicionados pesaron más que los becerros del tratamiento testigo $(P=0.019$, y $P=0.006$, para el Exp $1 ; P=0.048$, y $P=0.006$, para el Exp 3). En el Exp 2, realizado en época de lluvias, los becerros acondicionados y del grupo testigo tuvieron pesos similares al inicio, y a los días 0,28 , 56 y 84 posdestete.

\section{Ganancia diaria de peso (GDP)}

No se detectó interacción significativa entre acondicionamiento x sexo, ni efecto del sexo para GDP. Sin embargo, sí hubo efecto del acondicionamiento (T2), sobre el aumento de peso acumulado durante todo el período de evaluación (Figura 2).

Figura 2. Aumento diario de peso acumulativo (g/día) de becerros con acondicionamiento (barras azules) y sin acondicionamiento (barras rojas) en tres experimentos
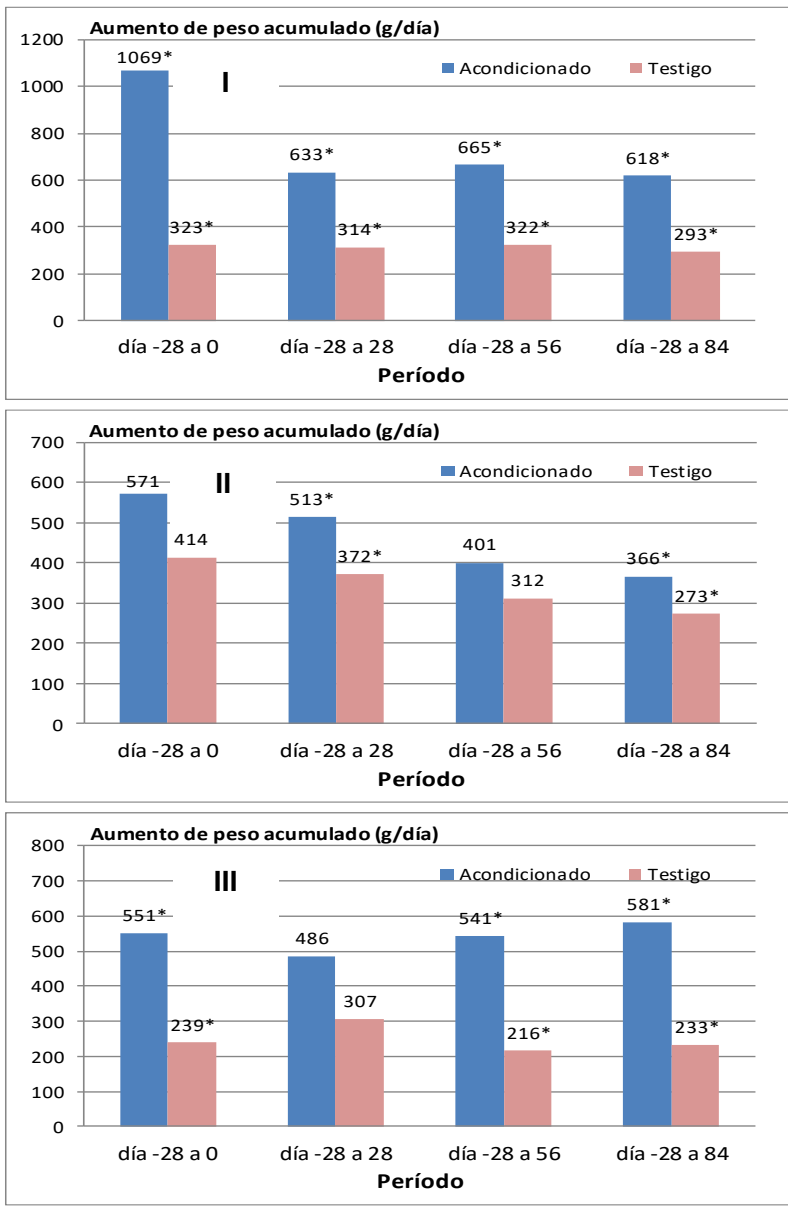

I= época seca $2012(P<0.001)$. II= época de lluvias 2012, aumentos de pesos entre periodos 1 y $2(P<0.05)$, aumentos de pesos entre los periodos 1 y 4 $(P=0.019)$. III= época seca 2013 , aumentos de peso periodos 1 y $4(P<0.001)$. 
En el Exp 1 la GDP acumulada para el T2 fue mayor $(P=0.001)$ durante todos los períodos. En el Exp 2, realizado en época de lluvias, la GDP de los becerros acondicionados fue mejor respecto al grupo testigo solo al considerar los 112 días del período experimental $(P=0.019)$. En el Exp 3, la GDP para los períodos $1(P=0.001), 3(P=0.001)$ y $4(P=$ $0.001)$, fue mejor en los becerros acondicionados que en el grupo testigo T1, mientras que en el período 2 la GDP fue similar entre tratamientos (486 vs $307 \mathrm{~g} / \mathrm{d} ; P=0.075)$.

\section{Valor nutricional de los pastos}

El forraje ofrecido en las parcelas pastoreadas por los becerros acondicionados a lo largo de los tres experimentos, tuvo un contenido de proteína similar al ofrecido a los becerros del grupo testigo (Figura 3). Solamente las muestras del pasto del día +56 del Exp 1, así como del día +28 del Exp 3, tuvieron contenido de proteína mayor al del pasto consumido por los becerros del tratamiento testigo. El contenido de fibra detergente neutro del pasto fue ligeramente

Figura 3. Contenido de proteína $(A, B, C)$ y de $\operatorname{FDN}(D, E, F)$ de pastos consumidos por los becerros acondicionados (rojo) y testigo (azul) en los tres experimentos

A

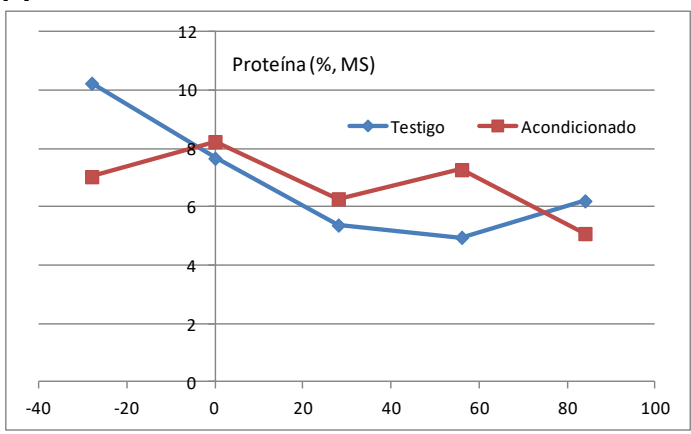

B

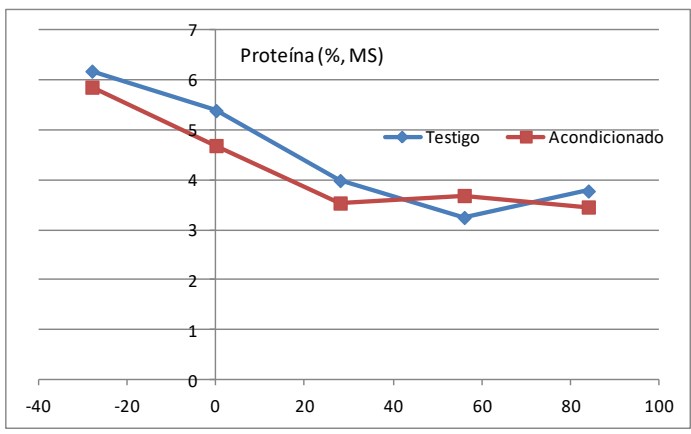

C

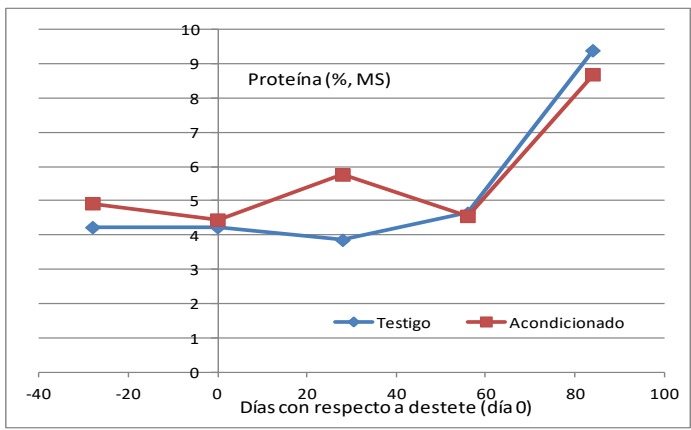

Experimento 1: A y D. Experimento 2: B y E. Experimento 3: $\mathrm{C}$ F.

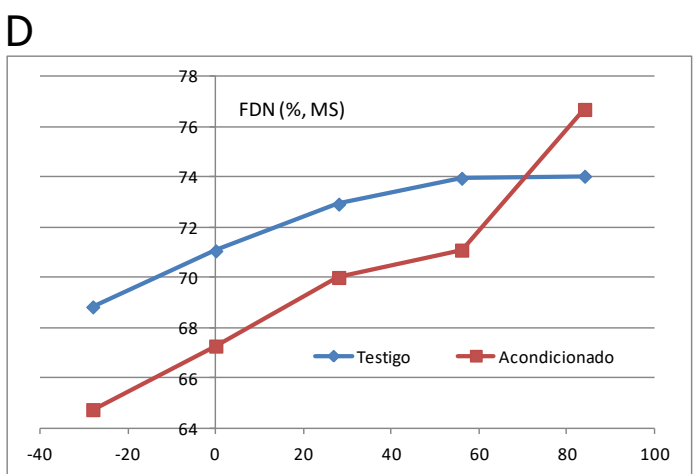

E

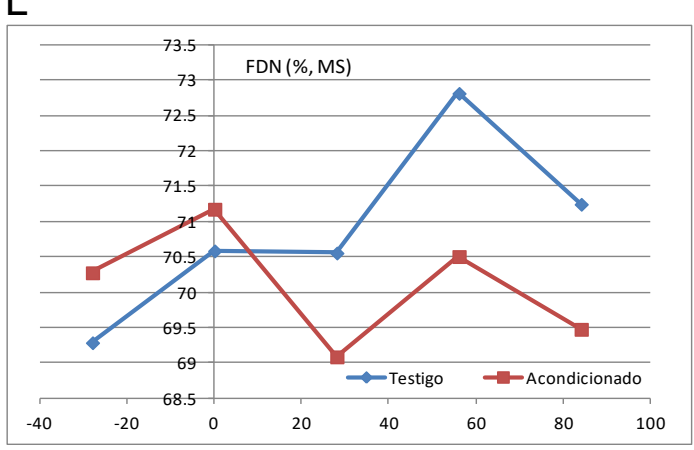

F

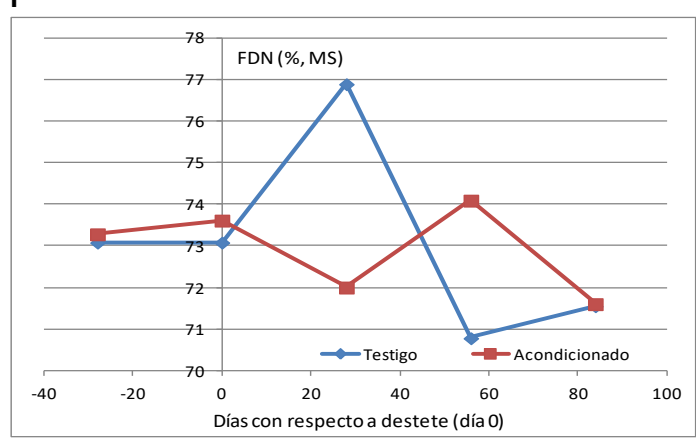


superior para los becerros del grupo testigo en varios periodos de los Exp 1 y 2, así como al día +28 del Exp 3.

\section{Nitrógeno ureico y glucosa}

Considerando los tres experimentos, no hubo interacción entre el acondicionamiento $x$ sexo. En general, no hubo diferencias entre sexos $(P=0.092)$, a excepción del día 56 posdestete en el Exp 2, cuando el contenido de nitrógeno ureico de los machos fue menor $(P=0.027)$ al de las hembras (10.2 vs $12.0 \mathrm{mg} / \mathrm{dl})$. En los $\operatorname{Exp} 1$ y 2 la concentración de nitrógeno ureico fue similar entre tratamientos (Cuadro 2) en la mayoría de las etapas; solamente al finalizar el período 2 del Exp 1, el $\mathrm{N}$ ureico de los becerros testigo fue mayor al de los becerros acondicionados ( $P=0.006)$. En el Exp 3, al finalizar los períodos 3 y 4 , las concentraciones séricas de $\mathrm{N}$ ureico de los becerros acondicionados fueron más altas $(P=0.041)$ que las del grupo testigo.

Cuadro 2. Concentración de nitrógeno ureico en la sangre de becerros sin (Testigo) y con (Acondicionados) acondicionamiento pre y pos destete $(\mathrm{mg} / \mathrm{dl})$

\begin{tabular}{|c|c|c|c|c|}
\hline- & Testigo & Acondicionados & \multicolumn{2}{|c|}{ EEM } \\
\hline \multicolumn{5}{|c|}{ Exp 1, época seca 2012} \\
\hline Al inicio & 17.4 & 16.0 & 0.92 & 0.267 \\
\hline Periodo 1 & 22.2 & 20.9 & 1.44 & 0.517 \\
\hline Periodo 2 & $21.2^{\mathrm{a}}$ & $19.4^{\mathrm{b}}$ & 0.35 & 0.006 \\
\hline Periodo 3 & 24.7 & 26.5 & 1.80 & 0.970 \\
\hline Periodo 4 & 19.4 & 15.5 & 2.14 & 0.149 \\
\hline \multicolumn{5}{|c|}{ Exp 2, época lluvias 2012} \\
\hline Al inicio & 16.0 & 14.4 & 1.20 & 0.350 \\
\hline Periodo 1 & 15.1 & 17.5 & 2.60 & 0.470 \\
\hline Periodo 2 & 18.3 & 18.4 & 2.52 & 0.975 \\
\hline Periodo 3 & 11.0 & 11.5 & 0.76 & 0.648 \\
\hline Periodo 4 & 10.2 & 9.8 & 0.73 & 0.686 \\
\hline \multicolumn{5}{|c|}{ Exp 3, época seca 2013} \\
\hline Al inicio & 18.0 & 20.6 & 0.91 & 0.064 \\
\hline Periodo 1 & 20.0 & 18.3 & 1.13 & 0.271 \\
\hline Periodo 2 & 26.2 & 29.1 & 1.17 & 0.085 \\
\hline Periodo 3 & $16.6^{\mathrm{b}}$ & $23.2^{\mathrm{a}}$ & 1.32 & 0.001 \\
\hline Periodo 4 & $26.1^{b}$ & $30.0^{a}$ & 1.39 & 0.041 \\
\hline
\end{tabular}

EEM= error estándar de la media. ab $(P<0.05)$.
Cuadro 3. Concentración de glucosa sanguínea de becerros sin y con acondicionamiento pre y pos destete $(\mathrm{mg} / \mathrm{dl})$

\begin{tabular}{lcccc}
\hline Variable & \multicolumn{3}{c}{ Acondicionamiento } & \\
& Sin & Con & EEM & $P$ \\
\hline Exp 1, época seca 2012 & & & \\
Al inicio & 72.0 & 60.3 & 3.80 & 0.036 \\
Periodo 1 & 48.8 & 50.2 & 3.00 & 0.740 \\
Periodo 2 & 68.8 & 70.2 & 3.10 & 0.740 \\
Periodo 3 & 88.0 & 78.1 & 3.99 & 0.084 \\
Periodo 4 & 69.2 & 76.0 & 4.69 & 0.307 \\
Exp 2, época lluvias 2012 & & & \\
Al inicio & 73.5 & 76.8 & 1.75 & 0.185 \\
Periodo 1 & 67.8 & 70.2 & 3.83 & 0.641 \\
Periodo 2 & $71.2 \mathrm{~b}$ & $79.9 \mathrm{a}$ & 3.06 & 0.046 \\
Periodo 3 & 72.3 & 73.2 & 3.67 & 0.860 \\
Periodo 4 & 56.2 & 57.8 & 3.13 & 0.711 \\
Exp 3, época seca 2013 & & & & \\
Al inicio & 65.8 & 70.8 & 2.46 & 0.156 \\
Periodo 1 & 59.3 & 61.4 & 2.68 & 0.590 \\
Periodo 2 & 71.2 & 72.7 & 2.40 & 0.655 \\
Periodo 3 & 68.5 & 72.4 & 1.81 & 0.140 \\
Periodo 4 & 68.1 & 70.4 & 2.54 & 0.538 \\
\hline EEM= error estándar de la media. & & & \\
ab (P<0.05). & & & & \\
& & & &
\end{tabular}

El contenido de glucosa sérica no mostró interacción significativa en acondicionamiento $x$ sexo. Tampoco hubo efecto del sexo. El acondicionamiento no ocasionó diferencias en el contenido de glucosa; excepto un contenido de glucosa sérica mayor de los becerros acondicionados $(P=0.046)$ al finalizar el periodo 2 del Exp 2 (Cuadro 3).

\section{Incidencia de enfermedades}

En los Exp 1 y 3, los becerros acondicionados tuvieron menos incidencia de enfermedades que los becerros del grupo testigo ( $P=0.001$; Cuadro 4). En el Exp 2, la incidencia de animales enfermos fue similar entre ambos tratamientos durante los 112 días que duró el estudio.

\section{Análisis económico}

En los Exp 1 y 3 los becerros acondicionados originaron un beneficio económico 63 y $71 \%$ mayor, 
Cuadro 4. Número y proporción (\%) de becerros enfermos y sanos sin y con acondicionamiento pre y pos destete

\begin{tabular}{lrrr}
\hline Variable & \multicolumn{4}{c}{ Acondicionamiento } & \\
& \multicolumn{1}{c}{ Sin } & \multicolumn{1}{c}{ Con } & $P$ \\
\hline Exp 1, época seca 2012 & & & \\
Animales enfermos & $10(62.5)$ & $2(12.5)$ & 0.001 \\
Animales sanos & $6(37.5)$ & $14(87.5)$ & \\
Exp 2, época lluvias 2012 & & & \\
Animales enfermos & $7(43.8)$ & $3(18.8)$ & 0.250 \\
Animales sanos & $9(56.2)$ & $13(81.2)$ & \\
Exp 3, época seca 2013 & & & \\
Animales enfermos & $11(68.8)$ & $5(31.2)$ & 0.001 \\
Animales sanos & $5(31.2)$ & $11(68.2)$ & \\
\hline
\end{tabular}

respectivamente, que los del grupo testigo (Cuadro 5). En cambio, en el experimento 2, realizado en la época de lluvias, el beneficio económico del acondicionamiento fue incluso $27 \%$ menor al del grupo testigo. En este análisis el mayor rubro de los costos variables fue el de la suplementación. El consumo promedio del suplemento por animal fue de $100.6,99.2$, y $127.2 \mathrm{~kg}$, respectivamente para los Exp 1, 2 y 3.

\section{DISCUSIÓN}

En el presente trabajo, el acondicionamiento de los becerros tuvo efectos benéficos sobre el aumento del peso corporal, la salud de los animales y los ingresos económicos, en comparación con los becerros del grupo testigo, especialmente durante la época seca del año.
En el destete de becerros, el cambio a una dieta sin leche, así como diferentes factores de estrés físico y psicológico asociados ${ }^{(28)}$, pueden afectar el comportamiento animal, así como su resistencia a algunas enfermedades infecciosas ${ }^{(29,30)}$. Diversas modalidades de destete se han probado, tratando de reducir efectos dañinos para los becerros ${ }^{(10,31)}$. Con el destete temprano, a 90 días, y a 150 días, la ganancia diaria de peso fue respectivamente de 875 y $995 \mathrm{~g} /$ día $(P<0.05)^{(31)}$. El acondicionamiento a becerros incrementó en $131 \mathrm{~g}$ el aumento diario de peso con respecto a los no acondicionados ${ }^{(10)}$. En los experimentos realizados en época de sequía, los aumentos de peso de los animales acondicionados fueron 208 y 246 g/día mayores a los del grupo testigo, respectivamente. En época de lluvias, los pesos fueron similares. Los incrementos de peso obtenidos en el presente estudio fueron similares a los reportados en condiciones tropicales ${ }^{(2,3)}$. Probablemente el contenido de proteína menor del pasto colectado en el Exp 2 respecto a los Exp 1 y 3 (Figura 3B vs $3 \mathrm{~A}$ y $3 \mathrm{C}$ ), pudo haber sido causa de que los becerros acondicionados no hubieran tenido mayor GDP en el Exp 2 (época de lluvias del 2012). El acondicionamiento de becerros registrado durante la época de sequía tuvo un efecto benéfico mayor, debido probablemente a que la suplementación compensó adecuadamente la reducida calidad nutritiva y digestibilidad de los pastos. La suplementación de becerros con un concentrado con $35 \%$ de proteína cruda (PC), a razón de $20 \mathrm{~g}$ de suplemento/kg de peso metabólico (Ej. $900 \mathrm{~g}$ de suplemento/día aportan $315 \mathrm{~g}$ de PC/día para un becerro de $160 \mathrm{~kg}$ peso vivo, y $1,160 \mathrm{~g}$ de suplemento/día aportan $406 \mathrm{~g}$ de PC/día para un

Cuadro 5. Análisis del costo de tratamientos y utilidad neta (miles de pesos mexicanos) de becerros sin y con acondicionamiento pre y pos destete ( $n=16$ por tratamiento)

\begin{tabular}{|c|c|c|c|c|c|c|}
\hline \multirow{3}{*}{ Variable } & \multicolumn{2}{|c|}{ Experimento 1} & \multicolumn{2}{|c|}{ Experimento 2} & \multicolumn{2}{|c|}{ Experimento 3} \\
\hline & \multicolumn{2}{|c|}{ Acondicionamiento } & \multicolumn{2}{|c|}{ Acondicionamiento } & \multicolumn{2}{|c|}{ Acondicionamiento } \\
\hline & Sin & Con & Sin & Con & Sin & Con \\
\hline Precio inicio & 82.68 & 83.57 & 92.53 & 90.89 & 131.82 & 128.60 \\
\hline Precio final & 104.99 & 130.86 & 113.55 & 118.88 & 149.68 & 173.09 \\
\hline Incremento de precio & 22.31 & 47.29 & 21.01 & 27.99 & 17.86 & 44.49 \\
\hline Costo de tratamientos & 2.21 & 14.47 & 2.21 & 14.31 & 2.21 & 17.71 \\
\hline Utilidad neta & 20.10 & 32.82 & 18.80 & 13.69 & 15.65 & 26.78 \\
\hline
\end{tabular}

La utilidad neta fue calculada como la diferencia del incremento de precio y el costo de los tratamientos, en cada experimento. 
becerro de $225 \mathrm{~kg}$ de peso vivo), permite tener ganancias diarias de peso superiores a $500 \mathrm{~g} / \mathrm{día}$ en becerros $^{(32)}$. Considerando el consumo, el contenido de proteína cruda del suplemento proporcionado, así como el contenido de proteína del forraje disponible en cada experimento, se estimó que el consumo de materia seca de forraje necesario para llenar las necesidades de proteína de los becerros ${ }^{(33)}$, debió ser 3,370 g/d en el Exp 1; 3,600 g/d en el Exp 2, y $3,585 \mathrm{~g} / \mathrm{d}$ en el Exp 3. Considerando además las tasas de degradabilidad ruminal de la proteína de los diferentes componentes dietarios ${ }^{(33)}$, se estimó que el concentrado suplementado tuvo $70 \%$ de proteína degradable. En ese caso, el aporte de proteína degradable suplementada varió de $220 \mathrm{~g} / \mathrm{d}(\operatorname{Exp} 1)$ a $280 \mathrm{~g} / \mathrm{d}$ (Exp 3). Se estima que la degradabilidad de la proteína de la dieta en los tres experimentos fuera de $64 \%$ en promedio, lo cual fue suficiente para satisfacer los requerimientos de proteína degradable en el rumen para becerros en crecimiento(33).

Las concentraciones séricas de glucosa y nitrógeno ureico $(\mathrm{NU})$ en becerros pueden variar durante la fase de crecimiento, debido a diversos factores fisiológicos ${ }^{(3)}$. Sin embargo, en el presente estudio, la concentración solamente varió en algunos períodos de los experimentos en la época de sequía. Concentraciones inferiores a $7.0 \mathrm{mg} / \mathrm{dl} \mathrm{de}$ sangre indican bajos contenidos de proteína degradable en la dieta, mientras que valores superiores a $19.6 \mathrm{mg} / \mathrm{dl}$ indican una situación inversa $^{(34)}$. En los tres experimentos se presentaron niveles normales de NU (entre 9.8 y $30.0 \mathrm{mg} \mathrm{dl}^{-1}$ ). En otro estudio(35), se reportaron valores de $\mathrm{NU}$ inferiores a los mínimos obtenidos en las dos épocas de sequía evaluadas en este trabajo $(15 \mathrm{mg} / \mathrm{dl})$, pero similares a los obtenidos en la época de lluvias del presente estudio, cuando, debido al valor energético y proteico de los pastos, los becerros utilizaron la proteína consumida para un mejor crecimiento, tal y como se observa en los aumentos de peso de los becerros que no fueron suplementados en el Exp 2, comparados con los de los Exp 1 y 3.

No hubo diferencias en la concentración de glucosa en sangre en los tres experimentos realizados, mientras que otros autores han registrado valores inferiores de glucosa en áreas tropicales en los meses de lluvias, principalmente, en animales adultos ${ }^{(35)}$. En el presente estudio el NU y la GS tuvieron valores considerados normales, sin efecto de los tratamientos probados, por lo que estas variables tienen poca asociación con los cambios de peso de los becerros.

Algunos parásitos pueden afectar a becerros en las primeras etapas de vida(36,37,38). La carga parasitaria registrada en el presente estudio osciló entre 100 y 300 huevos de parásitos gastroentéricos (ej. Strongyloides $s p p$.)/g de heces (HPG). Una desparasitación interna de los becerros con carga parasitaria mayor a 200 HPG durante la lactancia, puede mejorar en $6.5 \%$ la ganancia diaria de peso respecto a los no desparasitados ${ }^{(29,39)}$.

La incidencia de enfermedades se incrementó en los animales del grupo testigo, principalmente en los Exp 1 y 3, en los que el acondicionamiento sirvió como una medida preventiva contra algunas enfermedades de la región. En México hacen falta estudios que cuantifiquen el impacto de la incidencia de animales enfermos en esta fase de vida. En este país, apenas en el 2012 se confirmó la presencia de diarrea viral bovina en bovinos alojados en corral de finalización ${ }^{(40)}$. El acondicionamiento apoya al sistema inmunológico del becerro y le permite recuperar su salud y expresar su potencial genético y su status nutricional ${ }^{(37)}$. Una eventual presencia de estrés podría originar en los becerros no acondicionados un incremento en la presencia de enfermedades infecciosas ${ }^{(30)}$, como se observó en el presente estudio. El análisis económico realizado determinó el beneficio económico del acondicionamiento, expresado en términos de la diferencia entre los ingresos y los costos asociados a las prácticas zootécnicas realizadas. En la época de lluvias ( $\operatorname{Exp} 2)$, el acondicionamiento redujo en $27.2 \%$ el beneficio económico, respecto al de los becerros del grupo testigo. En cambio, durante la época de sequía, el acondicionamiento mejoró la utilidad neta en $63.2 \%$ (Exp 1) y en $71.1 \%$ (Exp 3).

\section{CONCLUSIONES E IMPLICACIONES}

Se concluye que el acondicionamiento pre-pos destete de becerros en el trópico seco, es una buena opción en el sistema vaca-becerro, principalmente 
durante la época seca, al evitar una reducción excesiva del peso y la condición corporal de las madres, y para mejorar la ganancia de peso y reducir la incidencia de enfermedades en los becerros y, consecuentemente, mejorar el ingreso del productor. Debido a la diversidad climática y de los sistemas productivos ganaderos, la realización de este tipo de estudios en otras regiones de México, puede aportar más información para incrementar la adopción de estas prácticas zootécnicas a mayor escala.

\section{AGRADECIMIENTOS}

Al personal del INIFAP (CIR-Noreste), por el apoyo en la realización de este estudio. Así como al cuerpo directivo, académico y personal de los laboratorios de la Facultad de Medicina Veterinaria y Zootecnia, y la Facultad de Agronomía de la UANL.

\section{LITERATURA CITADA}

1. Aban JA, Delgado R, Magaña JG, Segura JC. Factores que afectan el porcentaje de gestación a 120 días posparto en vacas cebú y cruzas con europeo en el sureste de México. Rev. AIA 2008;12(1):45-56.

2. Galli IO, Monje AR, Vittone S, Sampedro D, Busto C. Destete precoz: en Cría vacuna: Manual para la toma de decisiones y ejecuciones de la técnica. Serie Manual de la Cría vacuna, INTA EEA Concepción del Uruguay 2005;2:1-28.

3. Coppo JA, Coppo NB, Revidatti MA, Capellari A. Early weaning promotes improvement of blood nutritional indicators in half-bred zebu cows. Liv Res Rural Develop 2002;4:5. Article \#42. Retrieved June 29, 2017, from http://www.Irrd.org/Irrd14/5/copp145.htm.

4. Rodríguez QJI, Hernández CHE, Pérez GF, González GH, García SE, Pérez MA. Desarrollo de becerros en praderas durante la época de sequía en el Valle de la Paz, Baja California Sur. Reunión Anual Asociación Mexicana de Producción Animal, Cd. Victoria, Tamaulipas 2001:288-291.

5. Boyles SL, Loerch SC, Lowe GD. Effects of weaning management strategies on performance and health of calves during feedlot receiving. Prof Anim Sci 2007;23(6):637-641.

6. Lalman D, Hutson A, Shearhart W, Ward C, McKinley S. Preconditioning reduces sickness and death loss in weaned calves. J Anim Sci 2005;83:201-205.

7. Pritchard $\mathrm{RH}$, Mendez JK. Effects of preconditioning on pre- and post-shipment performance of feeder calves. J Anim Sci 1990;68:28-34.

8. Galyean $M L$, Perino $\mathrm{L}$, Duff GC. Interaction of cattle health/immunity and nutrition. J Anim Sci 1999;77:1120-1134.

9. Dhuyvetter K, Bryant AM, Blasi DA. Case study: Preconditioning beef calves: Are expected premiums sufficient to justify the practice? Prof Anim Sci 2005;502-514.
10. Mathis CP, Löest A, Carter B. Preconditioning beef calves. New Mexico State University and the U.S. Department of Agriculture cooperating. Las Cruces, N.M.; Circular 637:1-8. 2008.

11. Ávila GJ, Mena ST. Cuidado vaca-becerro ganado de carne y doble propósito. Congreso Nacional de Buiatría. AMMVZBAC. Monterrey, N.L. $2010 ; 10-18$.

12. Ibarra FFA, Moreno $\mathrm{CY}$, Martín RMH, Moreno MS, Denogean BF, Baldenegro CA, León MFL. El destete precoz como una herramienta para incrementar la rentabilidad en los ranchos ganaderos de Sonora, México. Rev Mex Agronegocios 2011;15(28):531-542.

13. Gamboa-Mena JV, Magaña-Magaña MA, Rejón-Ávila M, Pech MVC. Eficiencia económica de los sistemas de producción de carne bovina en el municipio de Tizimín, Yucatán. Trop Subtrop Agroecosyst 2005;5:79-84.

14. Kohn RA, Dinneen MM, Russek-Cohen E. Using blood urea nitrogen to predict nitrogen excretion and efficiency of nitrogen utilization in cattle, sheep, goats, horses, pigs, and rats. J Anim Sci 2005; 83:879-889.

15. Cooke RF, Arthington JD, Staples CR, Thatcher WW, Lamb GC. Effects of supplement type on performance, reproductive, and physiological responses of Brahman-crossbred females. J Anim Sci 2007;85:2564-2574.

16. Zorrilla RJM. El caso México. En: Zorrilla RJM et a/editores. Memoria Internacional: Escenarios futuros de la ganadería bovina para carne en México. Guadalajara, Jalisco. 2012:25-30.

17. García E. Modificaciones al sistema de clasificación climática de Köppen (para adaptarlo a las condiciones de la República Mexicana). Instituto de Geografía Universidad Nacional Autónoma de México. México, 1981.

18. Horn GW, McCollum, FT. Energy supplementation of grazing ruminants. Proc Grazing Livest Nutrition Conf 1987:125-136.

19. Lardy GP, Maddock TD. Creep feeding nursing beef calves. Veter Clinics North Amer: Food Anim Practice 2007;23(1):21-28.

20. Herd DB, Sprott LR. Body condition, nutrition and reproduction of beef cows. Texas farmer collection. Texas A\&M University System. 1998.

21. Bobadilla HAR, Castrejón PFA, Melgarejo VLG, Meraz RE. Manual de prácticas de producción y aprovechamiento de forrajes. Departamento Nutrición Animal y Bioquímica. UNAM. 2009:33-53.

22. AOAC. Official methods of analysis. 17th ed. Arlington, VA, USA: Association of Official Analytical Chemists. 2000.

23. Van Soest PJ, Robertson JB, Lewis BA. Methods for dietary fiber, neutral detergent fiber, and non-starch polysaccharides in relation to animal nutrition. J Dairy Sci 1991;74:3583-3597.

24. Cano CJP. Manual de prácticas de clínica de los bovinos 1ra. ed: Ávila GJ, et al editors. Fac. Med. Vet. y Zoot. UNAM (1994). http://www.fmvz.unam.mx/fmvz/licenciatura/coepa/archivos/Man uales/22_CLI NICA_BOVINOS.pdf. Consultado 5 nov, 2014.

25. Secretaría de Economía. Cuadro Comparativo Anual Nacional Pecuario. Bovinos: Ganado en Pie: Novillo. Sistema Nacional de Información e Integración de Mercados. 2015. http://www. economia- sniim.gob.mx/2010prueba/Cuadro-AnualConsPec.asp?per $=A \& x e d o=S \& x=36 \& y=16$. Consultado $5 \mathrm{Jul}, 2015$

26. SPSS. Statistical Package for Social Sciences. User's Manual (Release 17.0). Chicago. IL, USA: IBM Corp. 2008. 
27. Steel RGD, Torrie JH. Principles and procedures of statistics: A biometrical approach. $2^{\text {nd }}$ ed. New York, USA: McGraw-Hill Book Co; 1980.

28. Grandin T. Assessment of stress during handling and transport. J Anim Sci 1997;75:249-257.

29. Lucas AS, William S, Swecker DS, Lindsay GS, Elvinger FC, Zajac AM. The effect of weaning method on coccidial infections in beef calves. Vet Parasitol 2007;145:228-233.

30. Burke NC, Scaglia G, Boland HT, Swecker WS Jr. Influence of twostage weaning with subsequent transport on body weight, plasma lipid peroxidation, plasma selenium, and on leukocyte glutathione peroxidase and glutathione reductase activity in beef calves. Vet Immunol Immunopath 2009;127:365-370.

31. Blanco M, Villalba D, Ripoll G, Sauerwein H, Casasús I. Effects of early weaning and breed on calf performance and carcass and meat quality in autumn-born bull calves. Livest Sci 2009;120:103-115.

32. Balbuena O. Suplementación de destetes durante su primer invierno y de la vaquilla para primer servicio en el NEA. Seminario de Pasturas y suplementación estratégica en ganado bovino. Universidad Nacional de Asunción, Paraguay. 2002. http://www. produccionanimal.com.ar/informacion_tecnica/suplementacion/38suplementacion_destete_y_vaquilla.pdf. Accesado Jun 29, 2017.

33. NRC. Nutrient requirements of beef cattle, 7th rev. ed. Washington, DC: National Academy Press; 1996.
34. Cabrera NA, Elorza MP, Daniel RI. Efecto de tres suplementos proteicos sobre la ganancia de peso en becerros cebú/suizo que pastan en zacate Estrella de África (Cynodon plectostachyus). Rev UDO Agrícola 2005;5(1):103-106.

35. Marston TT, Lusby KS, Wettemann RP, Purvis HT. Effects of feeding energy or protein supplements before or after calving on performance of spring-calving cows grazing native range. J Anim Sci 1995;73:657-664.

36. Daugschies A, Najdrowski M. Eimeriosis in cattle: Current understanding. J Vet Med 2005;Series B, 52(10):417-427.

37. Brumbaugh GW. The immune system and recovery from sickness in cattle. The range beef cow Symp. Fort Collins, Co. 2007. http://beef.unl.edu/c13eabc6-48e9-45b8-8732-18682f9b38d6.pdf. Accessed Jun 29, 2017.

38. Ariasa RA, Maderb TL, Escobara PC. Factores climáticos que afectan el desempeño productivo del ganado bovino de carne y leche. Arch Med Vet 2008;40:7-22.

39. Hersom MJ, Myer RO, Carter JN. Influence on weaning weights of nursing beef cattle calves de-wormed 90 days prior to weaning. Livest Sci 2011;136:270-272.

40. Ramírez R, Chavarría B, López A, Rodríguez LE, Nevárez AM. Presencia del virus de la diarrea viral bovina y su asociación con otros cuadros patológicos en ganado en corral de engorda. Vet Méx 2012;43(3):225-234. 